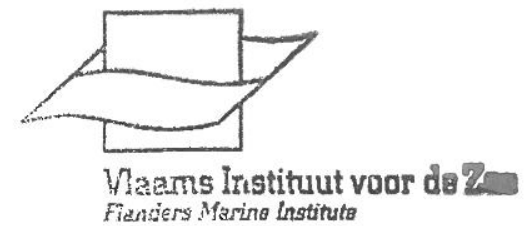

\title{
23808
}

\section{The water residence time in the Mururoa atoll lagoon: sensitivity analysis of a three-dimensional model}

\author{
B. Tartinville ${ }^{1}$, E. Deleersnijder ${ }^{1}$, J. Rancher ${ }^{2}$ \\ ${ }^{1}$ G. Lemaître Institute of Astronomy and Geophysics (ASTR), Catholic University of Louvain (UCL), 2 Chemin du Cyclotron,
B-1348 Louvain-la-Neuve, Belgium \\ ${ }^{2}$ Département d'Analyse et de Surveillance de l'Environnement, Commissariat à l'Energie Atomique, BP 208, F-91311 \\ Montlhéry Cedex, France
}

Accepted: 25 October 1996

\begin{abstract}
The role of oceanic tide, wind stress, hoa inflow and stratification in the long-term circulation in Mururoa lagoon is investigated using a sensitivity analysis carried out by means of a three-dimensional model. Water renewal time scales are estimated. Wind stress is shown to be the dominant forcing. The hoa inflow slightly increases the turnover time, while stratification enhances the impact of motion in vertical planes parallel to the wind stress. The modelled turnover time is approximately 100 days, and becomes much larger than one year whenever the wind stress is disregarded.
\end{abstract}

\section{Introduction}

Mururoa atoll is part of the Tuamotu Archipelago, French Polynesia, and is located in the tropical Pacific about $1300 \mathrm{~km}$ to the south-east of Tahiti at $138^{\circ} 55^{\prime} \mathrm{W}$ and $21^{\circ} 50^{\prime} \mathrm{S}$. The atoll lagoon is a semi-enclosed water body (Fig. 1), connected to the Pacific through a $5 \mathrm{~km}$ wide and $8 \mathrm{~m}$-deep pass, with a mean water depth of $33 \mathrm{~m}$. The atoll rim, the width of which is about $100 \mathrm{~m}$, is almost impermeable except in the southwestern part. In this region most of the reef is submerged, and channels (usually called "hoa") allow the oceanic swell to enter the lagoon (Fig. 1).

Since Mururoa atoll has been one of the test sites of French nuclear weapons, radioactive tracers could, sometime, be released into the lagoon and then exported towards the ocean (Ribbe and Tomczak 1990; Bourlat et al. 1995). Herein, only dissolved tracers that may be assumed to be passive are considered. A parcel of a passive tracer behaves as a water parcel. Therefore, the dynamics of these tracers depends on the hydrodynamics and, in particular, on the rate at which the lagoon water is renewed. The time scale of water renewal is also a parameter of

Correspondence to: $\mathrm{B}$. Tartinville

Fax: 32-10-47.47.22, e-mail: tartin@astr.ucl.ac.be crucial importance for the biological processes taking place in a lagoon. For instance, Hatcher and Frith (1985) showed that, in One Tree Reef lagoon, the long-term mean of the ammonium concentration is closely related to the residence time. Planktonic larvae distribution also depends on a relevant hydrodynamic time scale (Hatcher et al. 1987). The correlation between phytoplankton biomass and the time scale of water renewal was highlighted by Delesalle and Sournia (1992). Many other studies also pointed to the significant impact of hydrodynamics on the biological processes in atoll lagoons. Comprehensive study of the ecology of an atoll lagoon ecosystem must include the evaluation of appropriate hydrodynamic time scales.

Several authors (e.g. Gallagher et al. 1971; Bolin and Rodhe 1973; Zimmerman 1976; Kimmerer and Walsh 1981; Takeoka 1984) have suggested various ways of evaluating the water renewal time scale which may be applied to an atoll lagoon. The residence time at a given point in the lagoon is the period of time that a water parcel, initially located at the point considered, needs to leave the lagoon through the pass and enter the Pacific (Takeoka 1984). The turnover time is obtained by averaging the residence time over the volume of the lagoon. Using field data, the turnover time may be estimated as the ratio of the volume of the lagoon to the volume flux entering, or leaving the lagoon (Gallagher et al. 1971). However, if the residence time varies significantly in space, this method is unlikely to yield an acceptable estimate of the turnover time, as it is defined here. For instance, it is conceivable that a large fraction of the water entering the lagoon during the rising tide remains in the neighbourhood of the pass and leaves the lagoon as soon as the tide reverses. Consequently, the residence time is much smaller in the vicinity of the mouth of the lagoon than anywhere else. Only the water flux fuelling the long-term circulation in the lagoon should be introduced into the ratio referred to already. However, using in situ measurements to estimate this water flux is far from easy (Rancher and Chevalier 1989). Irrespective of this difficulty, by dividing the volume of the lagoon by the daily average of the incoming water flux, Rougerie et al. (1984) obtained a time scale of 


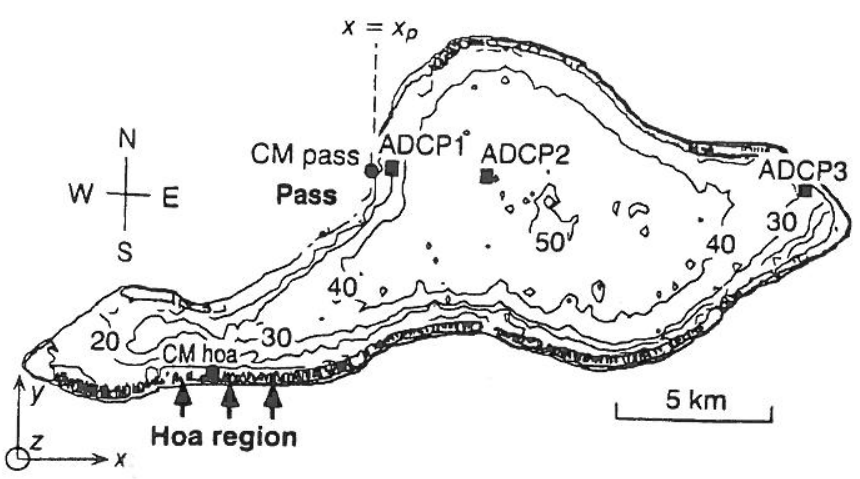

Fig. 1. Bathymetry of the Mururoa atoll lagoon. The contour interval is $10 \mathrm{~m}$. "CM pass" and "CM hoa" denote the locations of current meters moored in the pass and in the hoa, respectively. "ADCP1", "ADCP2" and "ADCP3" indicate the location of the acoustic Doppler current profiler. The horizontal axes are denoted $x$ and $y$, while $z$ is the vertical one. The eastern end of the pass is located at $x=x_{p}$

23 days, which must be regarded as the lower bound of the turnover time of the Mururoa lagoon.

The turnover time may also be derived from an appropriate analysis of the salt budget (Smith and Pesret 1974). For this method to be applicable, a series of conditions must be fulfilled. A significant salinity difference between the lagoon and the ocean is needed. The residence time must be sufficiently homogeneous in space. Finally, rainfall, evaporation, and the flow through the pass and the hoa, if any, must be monitored with sufficient accuracy. Kimmerer and Walsh (1981) estimated in this way the residence time in three sectors of Tarawa atoll lagoon. Rougerie et al. (1984) used similar means to calculate that the residence time of the deep eastern part of Mururoa lagoon is about 92 days.

Considering the discrepancy between the various time scales derived by Rougerie et al. (1984), we suggest that the residence time in Mururoa lagoon varies significantly in space. Moreover, the salinity difference between the lagoon and the ocean, though poorly known, is likely to be very small (Rougerie et al. 1984). Therefore, none of the methods alluded to may be optimal for estimating the turnover time of the Mururoa atoll lagoon. Consequently, we decided to investigate the potential of another approach, namely numerical modelling. A three-dimensional model of the lagoon hydrodynamics was set up. As will be seen, using a numerical model carries two distinct advantages. First, a numerical model enables a range of sensitivity analyses to be carried out, which help understand the hydrodynamics of the lagoon and the role of the various flow forcings. Second, in contrast to the techniques mentioned previously, a numerical model is capable of estimating the residence time with a high spatial resolution.

\section{Description of the model}

\section{The hydrodynamic module}

The equations of the hydrodynamic module derive from a series of hypotheses which are now standard (e.g. Nihoul
1984; Blumberg and Mellor 1987; Beckers 1991; Ruddick et al. 1995): the Boussinesq approximation is used, the hydrostatic balance is assumed to be valid, and the turbulent fluxes are parameterized with Fourier-Fick expressions involving diffusion coefficients. In particular, the eddy viscosity, $a_{v}$, and the eddy diffusivity, $k_{v}$, are computed from a popular turbulence closure scheme, namely the Mellor-Yamada level 2.5 model (Mellor and Yamada 1982) with quasi-equilibrium stability functions (Galperin et al. 1988; Deleersnijder and Luyten 1994). In the Mururoa lagoon, contributions by water density and atmospheric pressure variation to the horizontal pressure force are negligible. Therefore, only the effect of the sea surface slope is considered in the horizontal momentum budget.

According to available hydrographic data (Rancher 1995 ), variation in density over the water column is small compared to many marine flows: the vertical buoyancy gradient probably does not exceed an upper limit of $10^{-5}$ $\mathrm{s}^{-2}$. However, as indicated by our model results, current shear is such that the Richardson number, defined as the ratio of the vertical buoyancy gradient to the square of the shear frequency, may be close to 1 in many places, implying that stratification could have a significant impact on the turbulent energy budget and, hence, on eddy coefficients. Consequently, the density contrasts, though disregarded in the evaluation of the pressure force, must be taken into account in the turbulence closure model.

Density is a function of temperature and salinity, which may be computed from appropriate conservation equations. It is difficult to solve these equations for the Mururoa lagoon, owing to the scarcity of data which could provide relevant boundary conditions at the air-sea interface and at the lagoon mouth. Rather than solving the temperature and salinity equations, we prefer, as a makeshift, to ascribe a constant, hopefully reasonable value to the vertical buoyancy gradient needed in the turbulence closure scheme.

The hydrodynamic equations are solved in the sigmacoordinate system (e.g. Blumberg and Mellor 1987; Deleersnijder and Beckers 1992), using a finite-volume approach on Arakawa's C-grid. The horizontal grid size is $250 \mathrm{~m}$ and each water column is divided into 15 sigma levels. Most of the equations and numerical techniques used in the hydrodynamic module are well documented in the literature (see Gadd 1978; Patankar 1980; James 1986; Beckers and Deleersnijder 1993). However, the boundary conditions deserve some attention, particularly those closely related to the forcings of the flow in the Mururoa lagoon.

\section{The tracer transport module}

The concentration of a passive tracer obeys an advectiondiffusion equation. Such an equation may be modified so as to yield the residence time of the corresponding tracer (e.g. England 1995). Formulating appropriate open-sea boundary conditions for the residence time presents us with insuperable difficulties, prompting us to opt for an alternative, a Lagrangian method. With this approach, no boundary condition is needed at the mouth of the lagoon, while the residence time is readily determined. 
A small parcel of a passive tracer is subjected to transport processes only. As a numerical model is unable to represent all time and space scales of motion, it is necessary to distinguish the transport phenomena explicitly resolved from those appearing as subgrid-scale processes. The former are associated with the large-scale velocity computed by the hydrodynamic module, while the latter are usually parameterized as random walks amounting to diffusion (Allen 1982; Hunter et al. 1993). The large-scale motion of a Lagrangian particle is due to the velocity $\mathbf{u}+w \mathbf{e}_{z}$, where $\mathbf{u}, w$ and $\mathbf{e}_{z}$ denote the horizontal velocity vector, the vertical component of the velocity and the vertical unit vector, respectively.

Appropriate diffusivities are needed to determine the amplitude of the subgrid-scale motions. The vertical component of the random walks, mainly due to "real" turbulent phenomena, depends on the eddy diffusivity $k_{v}$. For want of an appropriate closure model, the diffusivity $k_{h}$, governing the magnitude of the horizontal random displacements, is assumed to be a function of the grid size only. Okubo's (1980) diffusion chart suggests taking $k_{h} \approx 0.02 \mathrm{~m}^{2} \mathrm{~s}^{-1}$. Obviously, the velocity field $\mathbf{u}+w \mathbf{e}_{z}$ and the eddy diffusivity $k_{v}$ are provided by the hydrodynamic module.

The position vector $\mathbf{r}$ of a Lagrangian particle may be updated as follows (Hunter et al. 1993):

$$
\begin{aligned}
\mathbf{r}(t+\Delta t)= & \mathbf{r}(t)+\Delta t\left\{\mathbf{u}+\left(6 k_{h} / \Delta t\right)^{1 / 2} \mathbf{d}_{h}\right. \\
& \left.+\left[w+\left(6 k_{v} / \Delta t\right)^{1 / 2} d_{v}+\frac{\partial k_{v}}{\partial z}\right] \mathbf{e}_{z}\right\},
\end{aligned}
$$

where $t$ and $z$ denote time and the vertical coordinate, respectively; $d_{v}$ and the components of the horizontal vector $\mathbf{d}_{h}$ are dimensionless random numbers uniformly distributed between -1 and +1 . The time increment $\Delta t$ is equal to 300 s, i.e. a value sufficiently small that several time steps are needed for a particle to leave a grid box. The terms in curly brackets in Eq. (1) are evaluated at time $t$ and location $\mathbf{r}(t)$.

In accordance with our working hypotheses, a Lagrangian particle may represent a certain amount of water or a relevant tracer. To determine the residence time, the particles are uniformly distributed in the lagoon at the initial instant $t=0$ : each grid box contains three particles, the masses of which are equal and proportional to the volume of the grid box considered. As time progresses, the trajectories of the water parcels are constructed by means of Eq. (1). It is assumed that every particle reaching the atoll mouth leaves the lagoon forever. In addition, the water entering the lagoon, through the pass or the hoa, is considered to be devoid of Lagrangian particles.

Ascribing to the initial position of a water, or tracer, parcel the time at which the latter leaves the lagoon, a position-dependent field of time scale is progressively constructed. This time scale is not regarded as the residence time since, owing to the stochastic nature of the Lagrangian approach, the fate of a single particle is meaningless. Only statistical quantities, related to a large number of particles, are relevant. Therefore, the residence time is actually defined to be a weighted average, taken over the neighbourhood of the point considered, of the time scale field based on the period of time needed for each Lagrangian particle to leave the lagoon.

\section{Design of the sensitivity analysis}

Here we report on the first step of the calibration and validation procedure of our model, i.e. a study of the sensitivity of the circulation and the water renewal time scales to the various flow forcings. A brief qualitative comparison is also carried out using velocity data collected by the SMSRB (Service Mixte de Surveillance Radiologique et Biologique de l'homme et de l'environnement of France).

Since the computational domain is restricted to the lagoon, the pass appears as an open boundary. The circulation is forced by the oceanic tide, the wind stress and the flow over the reef flat. The buoyancy fluxes at the surface, the lagoon mouth, and the hoa, which make up the thermohaline forcing are not explicitly represented in the present model, but result in stratification, the influence of which may be investigated in a schematic way.

The field data of Bourlat et al. (1995) point to the predominance of the trade winds in the region of Mururoa. Accordingly, it is assumed that the air velocity at $10 \mathrm{~m}$ above the sea level, $V_{a}$, is steady and westward. The wind stress is computed as $C_{a} \rho_{a} V_{a}^{2}$ (e.g. Busch 1977), where $\rho_{a}$ represents the air density $\left(\approx 1 \mathrm{~kg} \mathrm{~m}^{-3}\right)$ and $C_{a}$ is a dimensionless drag coefficient. The latter is taken to be $10^{-3}$, i.e. a value similar to those recommended for the modelling of flows in lakes (Graf et al. 1984).

Oceanic water may flow over a strip of the southern reef, the length of which is $L_{i} \approx 5 \mathrm{~km}$. Most of this water converges into the hoa (Fig. 1), and finally enters the lagoon. It is assumed that this inflow takes place over a water column of height $H_{i} \approx 1 \mathrm{~m}$ with a constant uniform velocity $V_{i}$, so that the total hoa inflow is given by $Q=L_{i} H_{i} V_{i}$.

The oceanic tide propagates into the lagoon through the pass. In the region of the Mururoa atoll, the semidiurnal M2 component, the period of which is $\approx 12.4 \mathrm{~h}$ is the dominant tidal signal (SHOM 1994). Herein only this tidal component is taken into account. The corresponding elevation is prescribed at the atoll mouth. An elementary scaling of the hydrodynamic equations suggests that neither the wind-induced circulation, nor the flow due to overbank flooding is likely to alter significantly the surface elevation in the vicinity of the atoll mouth. Therefore, prescribing the elevation at the pass on the sole basis of tidal data is justified. At the open sea boundary, the normal derivative of the horizontal velocity is ascribed to zero.

The bottom stress is computed as a quadratic function of the horizontal velocity in the grid box adjacent to the sea bed (e.g. Blumberg and Mellor 1987). The drag coefficient appearing in this parameterization involves the bottom roughness length, which is set as $0.04 \mathrm{~m}$ in the lagoon and $0.08 \mathrm{~m}$ in the neighbourhood of the pass. These values are adapted from the model study by Black (1993).

The sensitivity analysis consists of four model runs, conducted in a similar way. The sole difference between 
these simulations lies in the selection of the forcings. In the first model run the tidal forcing only is taken into account. Then, the wind stress, the hoa inflow and the stratification are successively included as steady state processes. The simulations are identified by letters related to the phenomena in question (Table 1): $T, W, H$, and $S$ refer to the tide, the wind stress, the hoa inflow, and the stratification.

The magnitude of the active forcings is derived from in situ measurements (Table 1). The amplitude of the M2 oceanic tide, $E$, is prescribed according to SHOM (1994). The wind velocity, $V_{a}$, is based on Bourlat et al. (1995). The incoming water velocity in the hoa region, $V_{i}$, is suggested by field data obtained by the SMSRB (Fig. 2). Finally, the vertical buoyancy gradient, i.e. the square of the BruntVäisälä frequency, $N$, is determined from Rancher (1995).

The tidal forcing is activated in all numerical experiments, so that a periodic hydrodynamic regime, independent of the initial conditions, prevails after a few days of simulation. As soon as such flow conditions are established the tracer transport module is started. Finally, the residence time and the turnover time are estimated. Note that a series of preliminary numerical experiments shows that the residence time and the turnover time are virtually equivalent whatever the initial instant of the tracer module, i.e. low tide, high tide, or any other moment.

Table 1. Characteristics of the numerical simulations. The amplitude of the M2 tidal signal imposed at the atoll mouth is denoted $E$, while $V_{a}, V_{i}$, and $N$ represent the westward air speed, the incoming water velocity in the hoa and the Brunt-Väisälä frequency, respectively

\begin{tabular}{|c|c|c|c|c|}
\hline & $E(\mathrm{~m})$ & $V_{a}\left(\mathrm{~m} \mathrm{~s}^{-1}\right)$ & $V_{i}\left(\mathrm{~m} \mathrm{~s}^{-1}\right)$ & $N^{2}\left(\mathrm{~s}^{-2}\right)$ \\
\hline Simulation $T$ & 0.3 & 0 & 0 & 0 \\
\hline Simulation $T W$ & 0.3 & 8 & 0 & 0 \\
\hline Simulation $T W H$ & 0.3 & 8 & 0.1 & 0 \\
\hline Simulation $T W H S$ & 0.3 & 8 & 0.1 & $10^{-5}$ \\
\hline
\end{tabular}

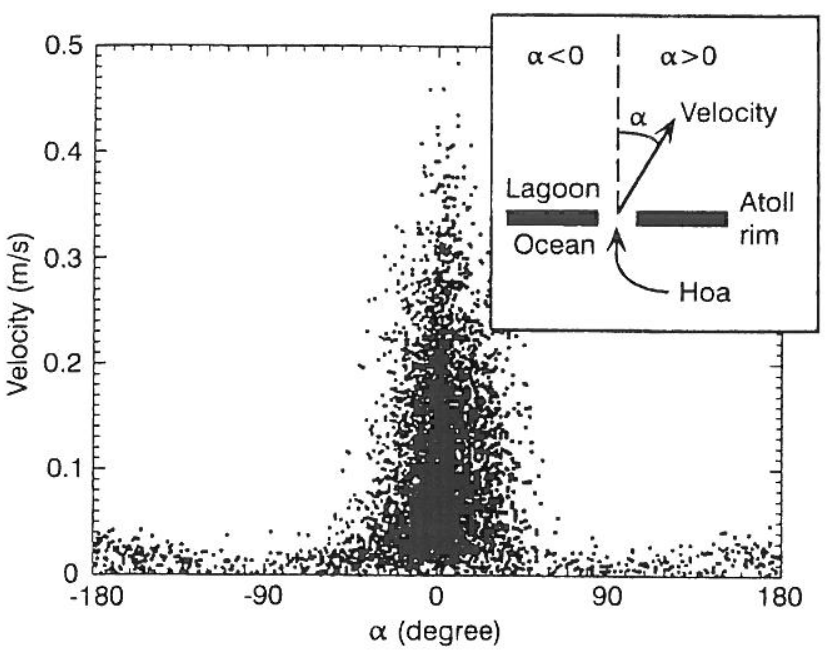

Fig. 2. Norm and direction of the velocity recorded in July and August 1995 by a current meter moored in a hoa at " $C M$ hoa" as indicated in Fig. 1. Water is entering the lagoon when $-90^{\circ} \leqslant x \leqslant 90^{\circ}$, and is leaving it otherwise
Model results and discussion

\section{Circulation}

In all simulations the modelled horizontal velocity compares rather well with the measurements made by a current meter "CM pass" (Fig. 1) moored near the northern end of the pass (Fig. 3). In this region the motion of the water is mainly due to the tide. Since it is the surface height rather than the velocity that is prescribed at the atoll mouth, Fig. 3 suggests that the tidal component of the velocity field may be satisfactorily simulated. However, as we are concerned with the long-term transport of water parcels, it seems natural that the analysis of the hydrodynamics be focused mostly on steady-state, tidally averaged quantities, i.e. the Eulerian residual circulation. It is worth pointing out that introducing the latter into the tracer transport module would yield water renewal time scales somewhat different from those obtained by
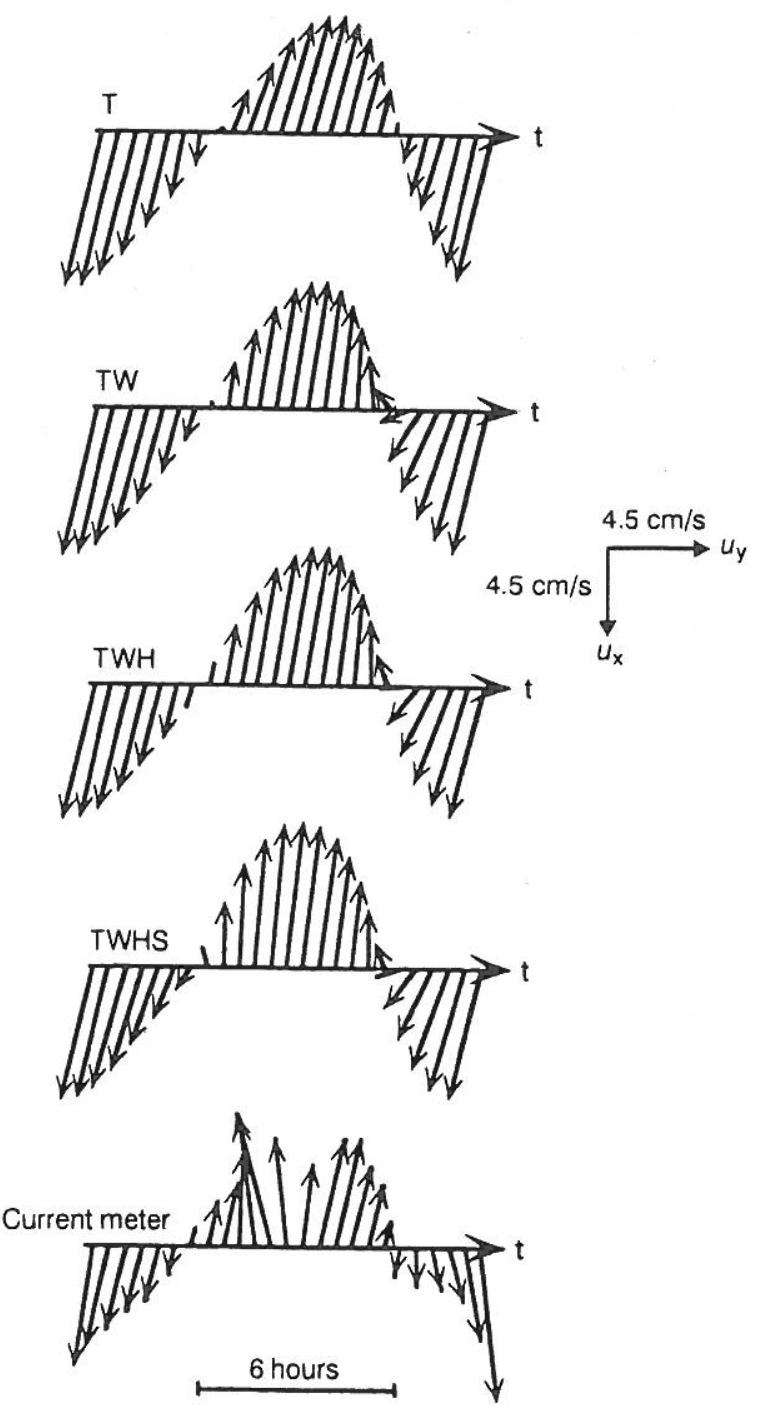

Fig. 3. The tidal cycle of the horizontal velocity at point " $C M$ pass" (Fig. 1) computed in simulations $T, T W, T W H$, and $T W H S$. The velocity recorded at the same point by a current meter in June 1995 is also displayed 
explicitly resolving the tidal cycle, which is the method actually selected here. Nonetheless, as will be seen, knowledge of the Eulerian residual provides useful clues to the understanding of the residence time field.

Let $a^{*}, \bar{a}$ and $\langle a\rangle$ represent the average over a tidal cycle, the depth-mean and the lagoon-average of the variable $a$, respectively. In addition, the deviation of $a$ with respect to its depth-mean is written as $\hat{a}=a-\bar{a}$. Finally, it is necessary to distinguish the eastward and the northward components of the horizontal velocity, $u_{x}$ and $u_{y}$, which are associated with the horizontal coordinates $x$ and $y$, respectively (Fig. 1).

Using these averaging operators, global characteristics of the lagoon hydrodynamics are defined and computed in Table 2 . Overall, the velocity components are much larger when the wind stress is activated. Switching on the hoa forcing hardly modifies the global features of the velocity field computed in Table 2. Imposing a weak stratification, as in simulation $T W H S$, reduces the turbulent viscosity and diffusivity by an order of magnitude.

In the wind-forced simulations the wind stress is equal to $6.4 \times 10^{-2} \mathrm{~kg} \mathrm{~m}^{-1} \mathrm{~s}^{-2}$, while the bottom stress rarely exceeds $10^{-2} \mathrm{~kg} \mathrm{~m}^{-1} \mathrm{~s}^{-2}$. Thus, it is the wind stress that sets the order of magnitude of the shear stress in the water column, which is parametrized as $\rho_{w} a_{v} \partial \mathbf{u} / \partial z$, where $\rho_{w} \approx 1025 \mathrm{~kg} \mathrm{~m}^{-3}$ is the water density. This explains why the decrease of viscosity due to stratification enhances $\hat{\mathbf{u}}$, and thus $\partial \mathbf{u} / \partial z$, in the TWHS simulation as compared with $T W$ and $T W H$ (Table 2).

Deeper insight into the lagoon hydrodynamics may be gained by examining two-dimensional quantities ensuing from the integral along a space coordinate of hydrodynamic variables. Adopting von Arx's (1948) approach, the horizontal circulation and the overturning motions are studied separately.
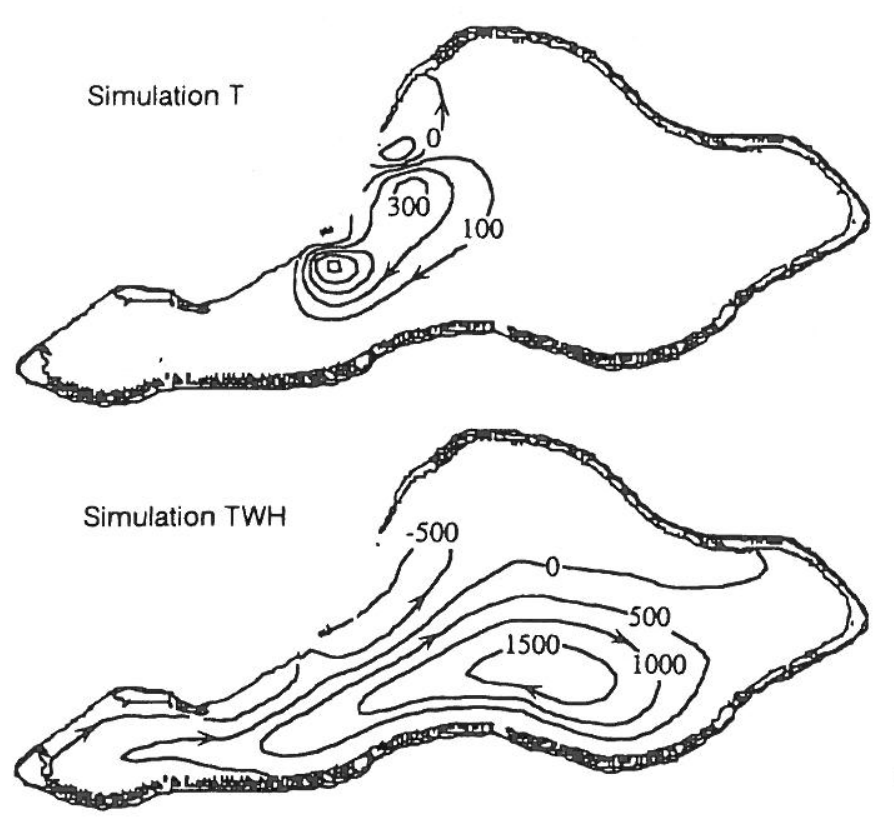

Fig. 4. Horizontal circulation obtained in simulations $T, T W$, $T W H$, and $T W H S$, as depicted by the stream function $\psi_{h}$. The
Table 2. Global features of the lagoon hydrodynamics obtained in simulations $T, T W, T W H$, and $T W H S$. The typical scales of the depth-mean current and the deviation with respect to this depth average in the $s$-direction $(s=x$ or $y)$ are denoted $\bar{U}_{s}$ and $\hat{U}_{s}$, respectively. The order of magnitude of the vertical velocity is represented by $W$, while $A_{v}$ and $K_{v}$ are characteristic values of the eddy viscosity and diffusivity, respectively. The horizontal and vertical velocity components are measured in $10^{-2}$ and $10^{-4} \mathrm{~m} \mathrm{~s}^{-1}$, respectively, while the eddy coefficients are expressed in $10^{-2} \mathrm{~m}^{2} \mathrm{~s}^{-1}$.

\begin{tabular}{lllll}
\hline & $T$ & $T W$ & $T W H$ & $T W H S$ \\
\hline $\bar{U}_{x}=\left\langle\left|\bar{u}_{x}{ }^{*}\right|\right\rangle:$ & 0.095 & 1.1 & 1.1 & 1.4 \\
$\widehat{U}_{x}=\left\langle\left|\hat{u}_{x}{ }^{*}\right|\right\rangle:$ & 0.015 & 1.9 & 1.9 & 2.3 \\
$\bar{U}_{y}=\left\langle\left|\bar{u}_{y}{ }^{*}\right|\right\rangle:$ & 0.074 & 0.48 & 0.51 & 0.75 \\
$\hat{U}_{y}=\left\langle\left|\hat{u}_{y}{ }^{*}\right|\right\rangle:$ & 0.0088 & 0.92 & 0.92 & 3.1 \\
$W=\left\langle\left|w^{*}\right|\right\rangle:$ & 0.070 & 1.1 & 1.1 & 2.1 \\
$A_{v}=\left\langle a_{v}{ }^{*}\right\rangle:$ & 0.023 & 1.1 & 1.1 & 0.18 \\
$K_{v}=\left\langle k_{v}{ }^{*}\right\rangle:$ & 0.028 & 1.4 & 1.4 & 0.20 \\
\hline
\end{tabular}

The horizontal, Eulerian residual is best characterized by the transport $\left[\left(h \bar{u}_{x}\right)^{*},\left(h \bar{u}_{y}\right)^{*}\right]$, where $h$ is the height of the water column. It is readily seen that this transport is divergence-free, implying that it may be represented with the help of the stream function $\psi_{h}$ as follows:

$\left[\left(h \bar{u}_{x}\right)^{*},\left(h \bar{u}_{y}\right)^{*}\right]=\left(-\frac{\partial \psi_{h}}{\partial y}, \frac{\partial \psi_{h}}{\partial x}\right)$.

Activating the wind forcing increases greatly the intensity of the horizontal residual circulation (Fig. 4), which may be measured by the range of $\psi_{h}$. It is not known why the range of $\psi_{h}$ varies little throughout the series of windforced simulations.

When the tide is the only forcing, the residual transport exhibits a slow, clockwise pattern in the vicinity of the pass and is negligible elsewhere. If the wind stress is
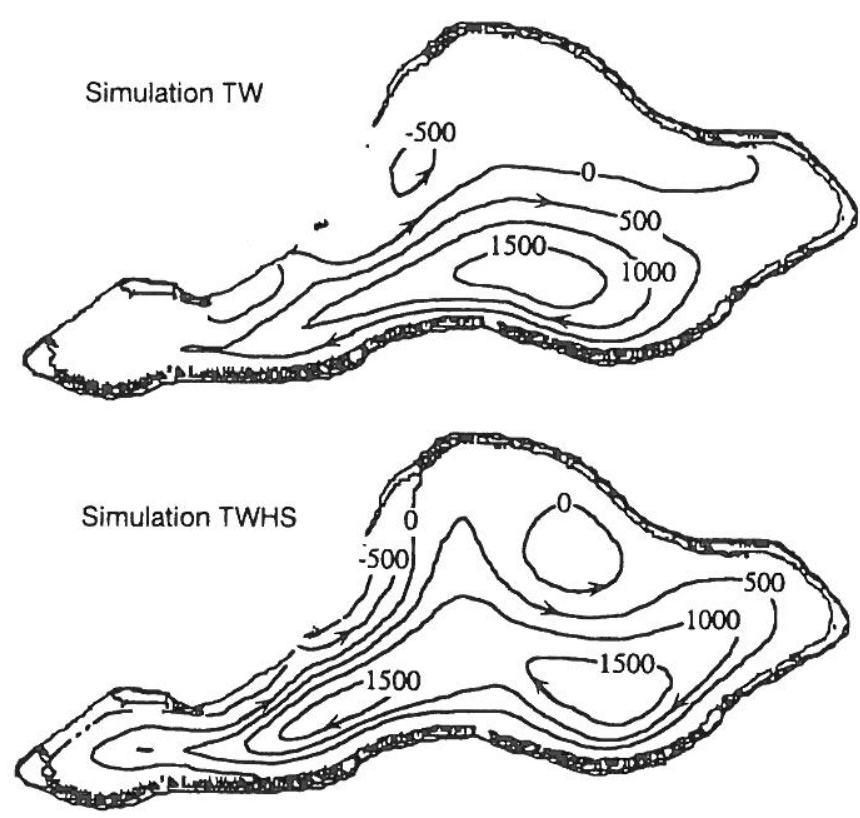

contour interval is $100 \mathrm{~m}^{3} \mathrm{~s}^{-1}$ for simulation $T$ and $500 \mathrm{~m}^{3} \mathrm{~s}^{-1}$ for the other model runs 
applied, a noticeable residual circulation is present in most of the lagoon. In particular, a large clockwise gyre develops. The transport in the southwestern tip of the lagoon is negligible if the hoa forcing is zero. Allowing water to flow through the hoa slightly modifies the overall residual circulation, because most of the hoa water flows directly from the hoa region to the atoll mouth. When stratification is taken into account, the shape of the residual gyre differs from that obtained in the $T W$ and $T W H$ simulations.

In Bikini and Rongelap lagoons von Arx (1948) found a two-layer overturning circulation pattern in vertical planes parallel to the wind stress. The upper layer, in which, on average, the water flows downwind, lies on top of a return-flow layer. The circulation is closed by upwelling near the windward reef and downwelling on the leeward side. The acoustic Doppler current profiler (ADCP) measurements displayed in Fig. 5 seem to be consistent with this circulation scheme. The modelled velocity, obtained in wind-forced cases, agree qualitatively with these data (Fig. 5), while the tide-only velocity is much smaller.

To perform a more global analysis of the velocity field, we calculate the integral of $u_{x}^{*}$ and $w^{*}$ over $y$ from the southern reef $\left(y=y_{s}\right)$ to the northern $\left(y=y_{n}\right)$. To the east of the lagoon mouth (Fig. 6), this yields a divergence-free transport field which may be derived from the overturning stream function $\psi_{o}$ :

$\int_{y_{s}}^{y_{n}}\left(u_{x}^{*}, w^{*}\right) d y=\left(\frac{\partial \psi_{o}}{\partial z},-\frac{\partial \psi_{o}}{\partial x}\right)$.

The circulation patterns depicted in Fig. 6 clearly involve an overturning motion, except for the tide-only case. In simulation $T, \psi_{o}$ is an order of magnitude smaller than in the wind-forced cases and the circulation is confined to the neighbourhood of the pass. In $T W$ and $T W H$ the height of the surface layer is 10 to $20 \mathrm{~m}$ and the strength of the overturning circulation is almost equivalent, since the hoa flow overwhelmingly influences the south-western part of the domain. Including the stratification hardly modifies the range of $\psi_{o}$, but significantly alters the circulation pattern. Indeed, in model run $T W H S$, a three-layer sketch best typifies the circulation. The surface layer is shallower, exhibiting a depth of approximately $10 \mathrm{~m}$. The intermediate layer bears most of the return flow, whereas the bottom layer consists of water which is, on average, almost motionless. In other words, the intensity of the overturning circulation is similar in all wind-forced cases, but in TWHS the overturning cell is shallower, so that the velocity and the velocity shear are larger (Table 2 ).

To the east of the pass, in vertical planes orthogonal to the wind stress, an overturning circulation also takes place, exhibiting downwelling along the southern part of the atoll rim and upwelling along the northern. The conditions for this circulation to be represented by a stream function are not fulfilled. Nevertheless, it is worth examining the northward residual transport, $q$, obtained by integrating $u_{y}^{*}$ over $x$ from the pass $\left(x=x_{p}\right)$ (Fig. 1) to the eastern boundary of the lagoon $\left(x=x_{e}\right)$, i.e.

$q=\int_{x_{p}}^{x_{p}} u_{y}^{*} \mathrm{~d} x$
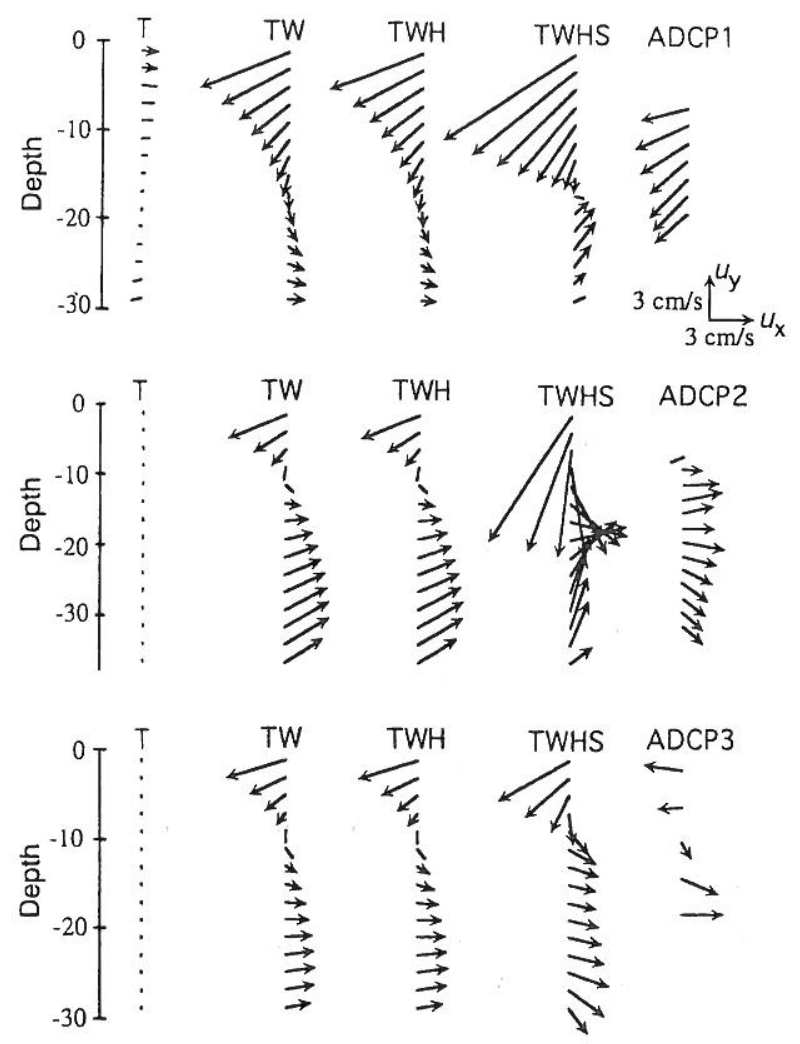

Fig. 5. Vertical profiles of the tidally averaged horizontal velocity simulated in $T, T W, T W H$, and $T W H S$ at points " $A D C P 1$ ", $A D C P 2$ ", and " $A D C P 3$ " (Fig. 1). ADCP measurements made along the same verticals, and averaged over a tidal cycle in June 1995, are shown in the furthest right column

The latter is one to two orders of magnitude smaller when the tide is the sole forcing activated (Fig. 7). If the wind stress is taken into account, the water flows, on average, southward near the surface and northward at depths greater than 10 to $20 \mathrm{~m}$, which is qualitatively in agreement with the Ekman veering theory. The northward transport is almost equivalent in simulations $T W$ and $T W H$, but is about five times larger in TWHS. This is consistent with the values in Table 2 , showing that $\hat{U}_{y}$ and $W$ are much smaller when the water column is assumed to be homogeneous.

\section{Residence time}

The Eulerian residual transports examined in the preceding section exhibit large-scale, well-defined cells, which are conveniently referred to as "horizontal gyre", "overturning motion", etc. Unfortunately, this does not necessarily imply that the Lagrangian particles are likely to follow the streamlines of the horizontal or overturning circulations, for one velocity component as well as the diffusive phenomena are systematically ignored in these appealing, yet incomplete, graphic representations. To sort out the actual impact of the hydrodynamic processes on the longterm transport of water parcels, it is necessary to measure the importance of each of them. Such a measure may be 

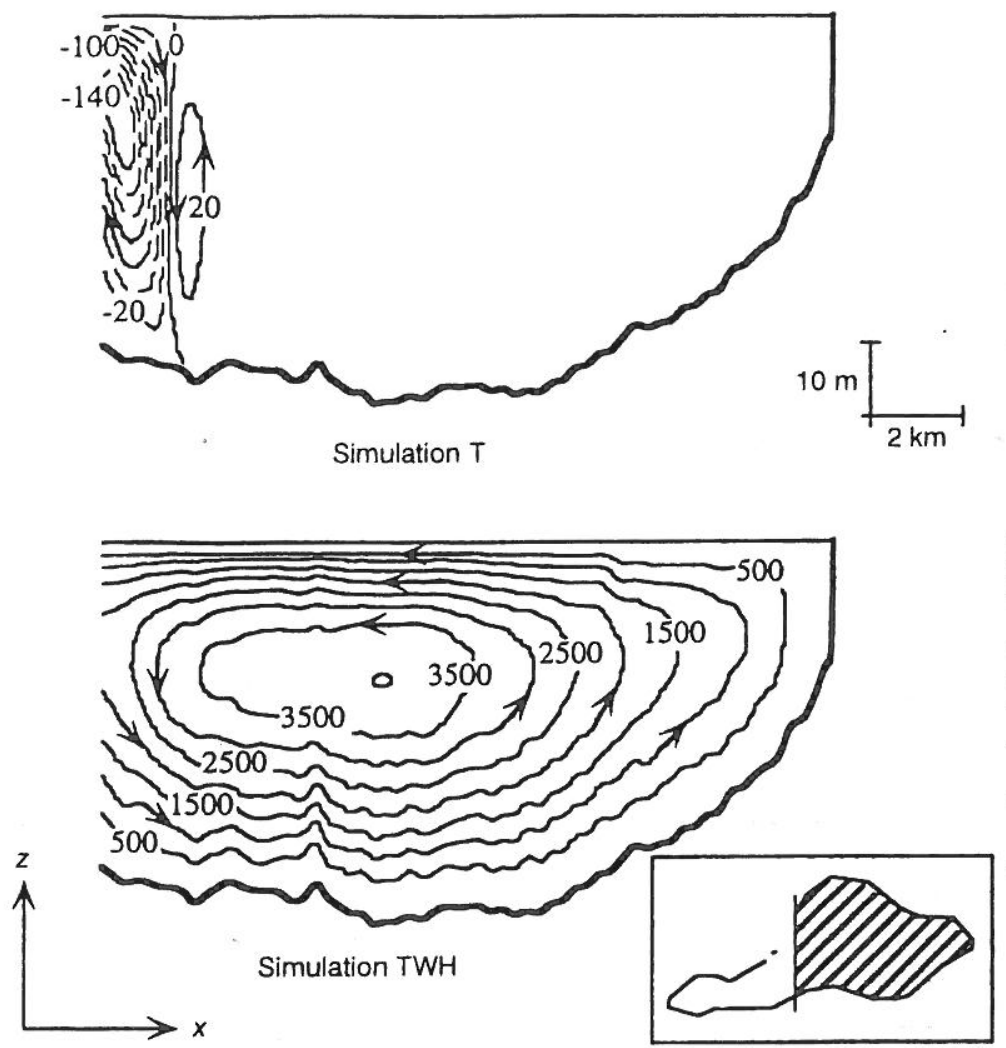
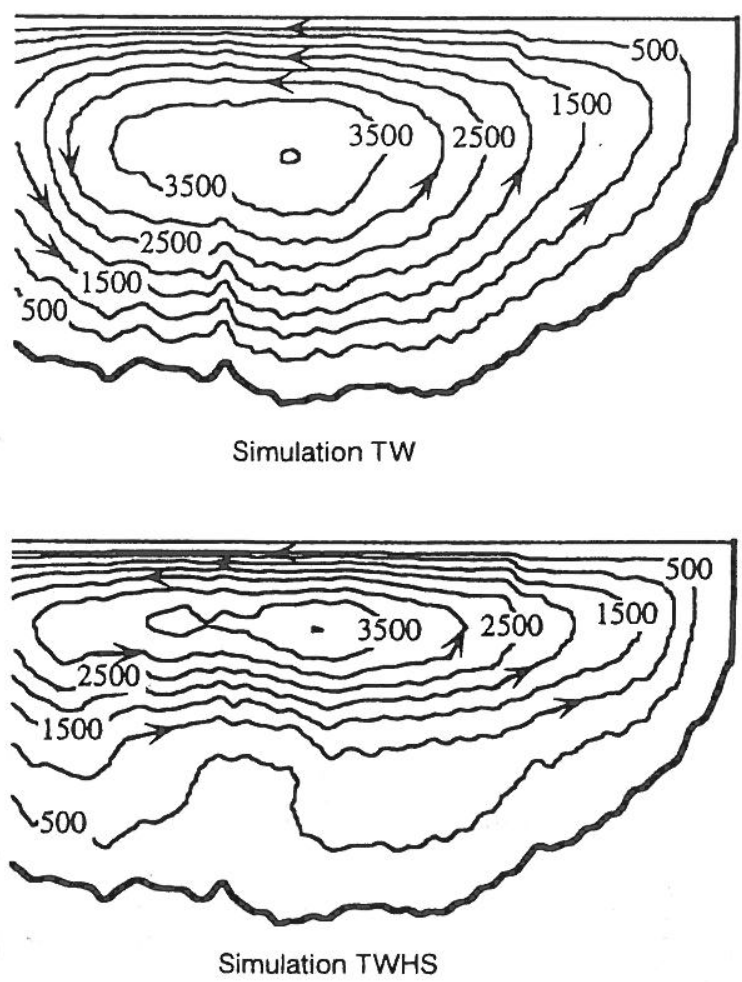

insert according to Eq. 3. The contour interval is $20 \mathrm{~m}^{3} \mathrm{~s}^{-1}$ for simulation $T$ and $500 \mathrm{~m}^{3} \mathrm{~s}^{-1}$ for the other model runs
Fig. 6. Overturning stream function $\psi_{o}$ from simulations $T, T W$, $T W H$, and $T W H S$ computed in the hatched area depicted in the a time scale (Table 3): the shorter the characteristic time of a given phenomena is, the more important, or the "faster", this phenomena is.

The time scales of horizontal diffusion, $T_{x}^{d}$ and $T_{y}^{d}$, are much larger than the other characteristic times. Thus, at the lagoon scale, horizontal diffusion is the weakest phenomenon. However, the smallest resolved features, the length scale of which is of the order of the grid size, exhibit a horizontal diffusion time scale of about 10 days, which explains why discernible modifications of the residence time distribution arise when $k_{h}$ is set to zero. In all numerical experiments, the smallest time scale is that associated with vertical diffusion. It is thus not surprising that vertical variation of the residence time is small compared with the turnover time, implying that it is sufficient to analyse the depth-average of the residence time (Fig. 8). All horizontal advection time scales are largest in simulation $T$, which is why this simulation leads to a residence time which is overall much larger than in the other model runs. As the wind-forced residual circulations bear no resemblance to that of the tide-only simulation, it is quite natural that the corresponding residence time distributions are completely dissimilar.

We put forward the hypothesis that the large horizontal gyres characterizing the $T W$ and $T W H$ depth-mean residual circulation tend to trap water parcels, an assumption clearly supported by the maximum of the residence time approximately coinciding with the gyre center. The time scales evaluated in Table 3 also point to the importance of vertical diffusion and advection by the deviation of the horizontal velocity. The combined action of these processes probably allows the Lagrangian particles to escape from the horizontal gyres. This mechanism amounts to a special type of horizontal mixing (e.g. Bowden 1965) and is often called "shear effect". As vertical diffusion seems to be faster than vertical advection, the role of the latter may be of lesser importance.

There are a number of clues indicating that, in simulations $T W$ and $T W H$, the overturning motions do not play a dominant role in the long-term water transport. In fact, with these forcings, the depth-mean advection and the shear effect mixing are likely to be the most important phenomena. Numerical simulations in which the vertical velocity is set to zero in the tracer module yield results consistent with this assumption.

When the buoyancy gradient is taken into account, the horizontal residual gyre is still present, but the residence time is, roughly speaking, a function of the distance to the atoll mouth, which no longer reflects a gyre trapping effect. In $T W H S$ there is a marked decrease of $T_{y}^{a}$ and $T_{v}^{a}$, as compared with $T W$ and $T W H$ values, suggesting that the shear effect and the overturning circulation in northsouth vertical planes may play an important role. In other words, when stratification is present, water parcels may exhibit a strong tendency to move in vertical planes orthogonal to the wind stress (Fig. 9), which is consistent with 


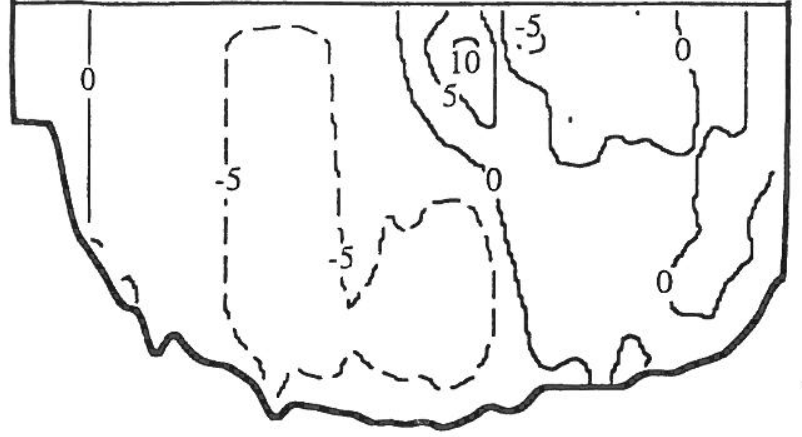

Simulation $T$

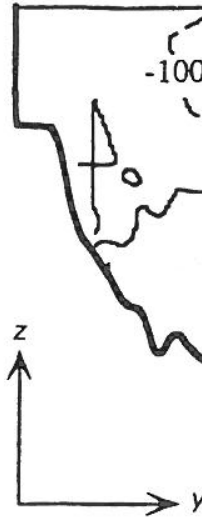

Fig. 7. The northward transport $q$ from numerical experiments $T$, $T W, T W H$, and $T W H S$. The hatched area in the insert is the domain where $q$ is computed in accordance with Eq. 4 . The contour

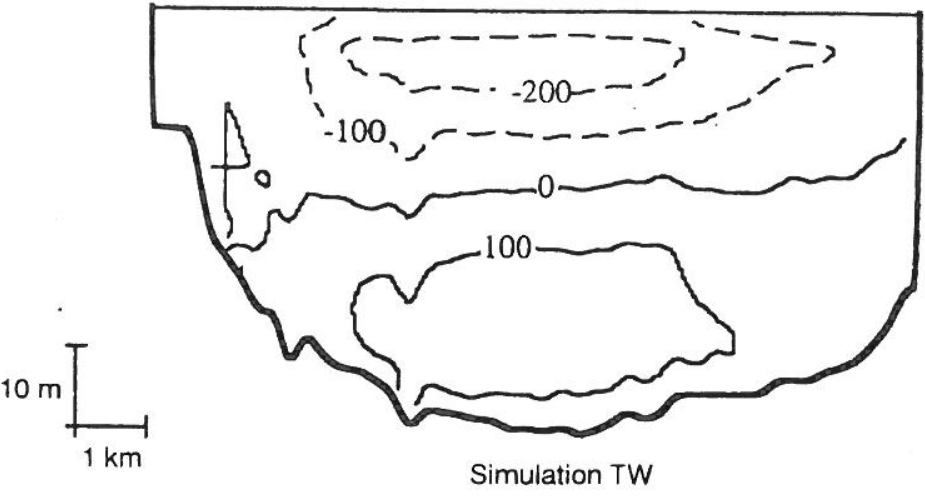

Simulation TW

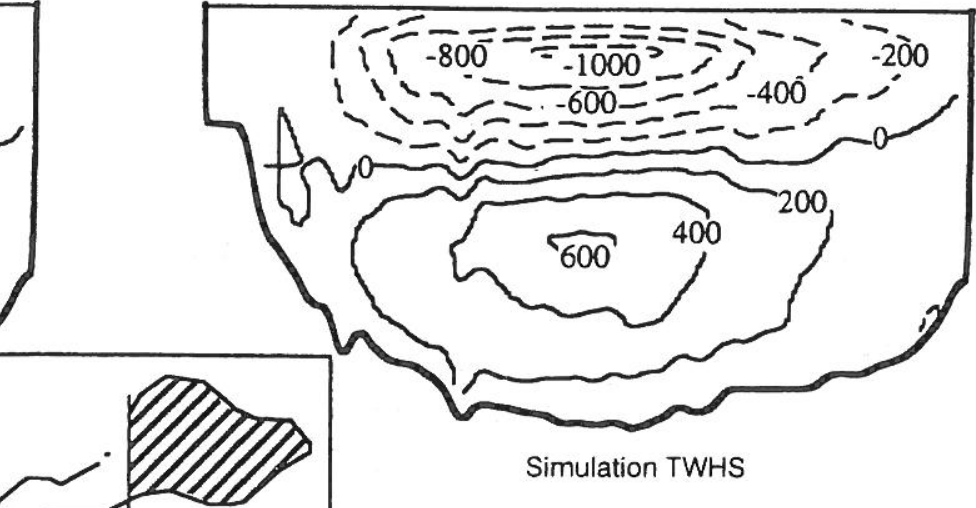

Table 3. Time scales of residual transport processes diagnosed from the results of model runs $T, T W, T W H$, and $T W H S$. The horizontal advection along the $s$-axis $(s=x, y)$ by the depth-averaged velocity and the deviation with respect to the depth-mean current exhibit characteristic times $\bar{T}_{s}^{a}$ and $\hat{T}_{s}^{a}$, respectively. The vertical advective time scale is denoted $T_{v}^{a}$, while $T_{s}^{d}$ and $T_{v}^{d}$ represent the horizontal and vertical characteristic times of diffusive processes. The quantities $L_{x}=10^{4} \mathrm{~m}$ and $L_{y}=5 \times 10^{3} \mathrm{~m}$ are the horizontal length scales in the $x$ and $y$ directions. The typical height of the water column is taken to be $H=30 \mathrm{~m}$. All time scales are expressed in days

\begin{tabular}{lrccc}
\hline & $T$ & $T W$ & $T W H$ & $T W H S$ \\
\hline $\bar{T}_{x}^{a}=L_{x} / \bar{U}_{x}:$ & 120 & 11 & 11 & 8.3 \\
$\hat{T}_{x}^{a}=L_{x} / \hat{U}_{x}:$ & 770 & 6.1 & 6.1 & 5.3 \\
$\bar{T}_{y}^{a}=L_{y} / \bar{U}_{y}:$ & 78 & 12 & 11 & 7.7 \\
$\hat{T}_{y}^{a}=L_{y} / \hat{U}_{y}:$ & 660 & 6.3 & 6.3 & 1.9 \\
$T_{v}^{a}=H / W:$ & 33 & 2.1 & 2.1 & 1.1 \\
$T_{x}^{d}=L_{x}^{2} /\left(\pi^{2} k_{h}\right):$ & 5900 & 5900 & 5900 & 5900 \\
$T_{y}^{d}=L_{y}^{2} /\left(\pi^{2} k_{h}\right):$ & 1500 & 1500 & 1500 & 1500 \\
$T_{v}^{d}=H^{2} /\left(\pi^{2} K_{v}\right):$ & 3.8 & 0.075 & 0.075 & 0.53 \\
\hline
\end{tabular}

the iso-lines of the residence time being generally parallel to the $y$-axis, at least to the east of the lagoon mouth. In all wind-forced experiments, the Lagrangian particles follow highly meandering trajectories, which is the reason why

interval is $5 \mathrm{~m}^{2} \mathrm{~s}^{-1}, 100 \mathrm{~m}^{2} \mathrm{~s}^{-1}$, and $200 \mathrm{~m}^{2} \mathrm{~s}^{-1}$ for simulations $T$, $T W$ or $T W H$, and $T W H S$, respectively

the advective time scales are much smaller than the turnover time.

\section{Turnover time}

In all numerical simulations, a few particles are trapped in the lagoon for an exceedingly long time. Carrying on with the computations until all marked water parcels have entered the Pacific would tend to overestimate the turnover time. This problem is circumvented using the statistical analysis outlined later.

If $m(t)$ denotes the total mass of the Lagrangian particles remaining in the lagoon at time $t$, then the turnover time, $\theta$, may be calculated as

$\theta=-\int_{0}^{\infty} \frac{1}{m(0)} \frac{\mathrm{d} m}{\mathrm{~d} t} t \mathrm{~d} t$

which may be seen to be equivalent to the definition given previously.

The space distribution of the mass of the Lagrangian particles is almost uniform in the lagoon, suggesting that the hydrodynamics results in an efficient three-dimensional mixing. Therefore, the probability that a given marked water parcel is at a point where it is likely to leave 


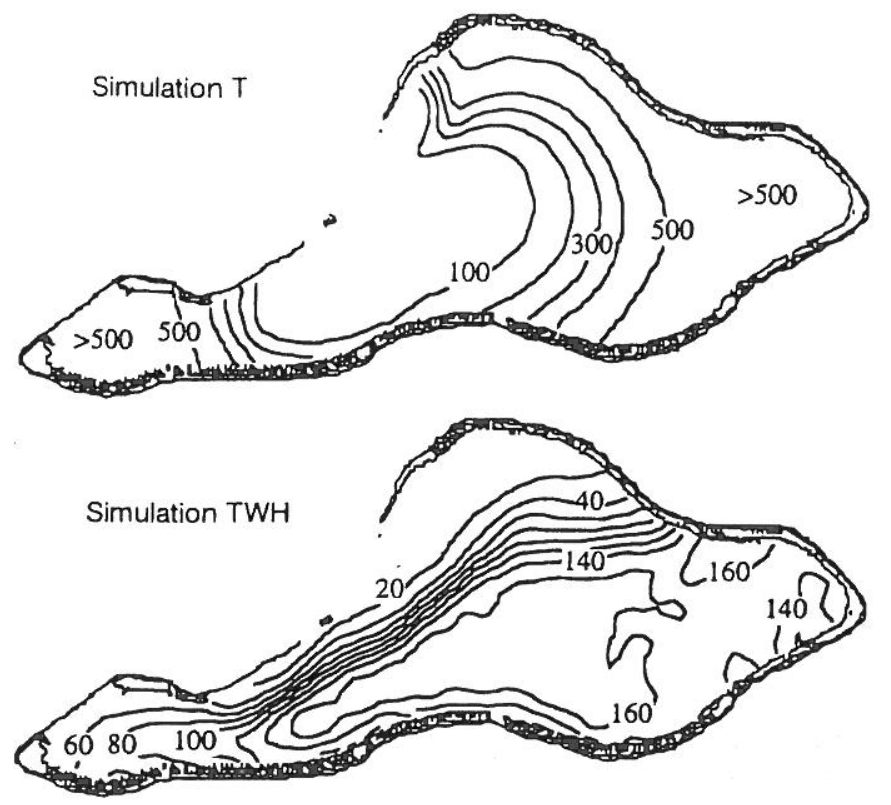

Fig. 8. Depth-averaged residence time obtained in simulations $T, T W, T W H$, and $T W H S$. The contour interval is

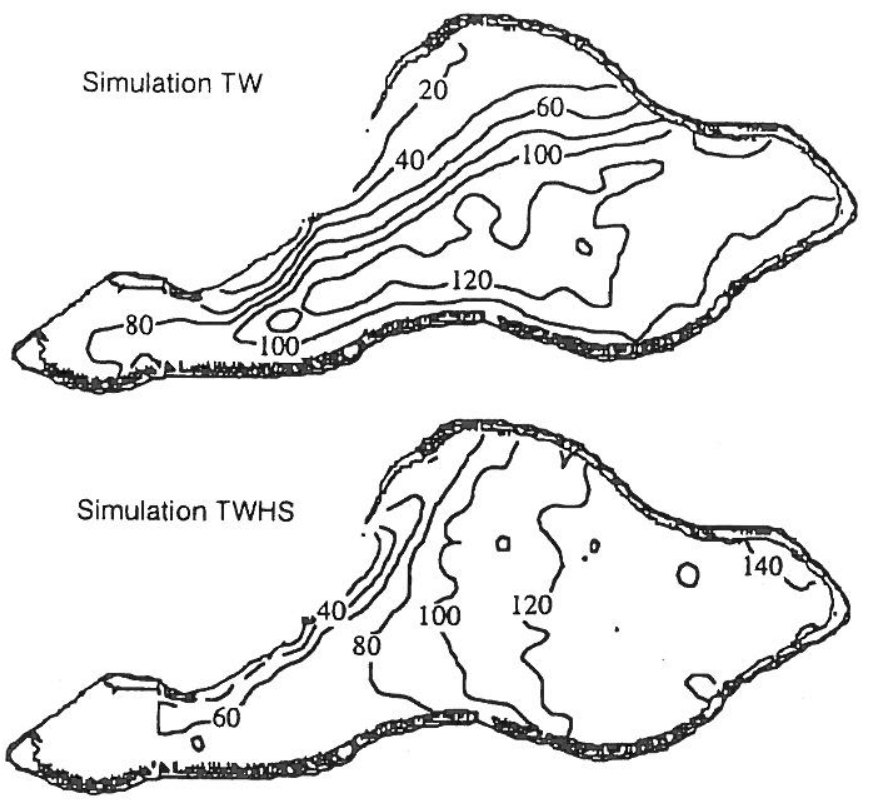

100 days for model run $T$ and 20 days for the other numerical experiments

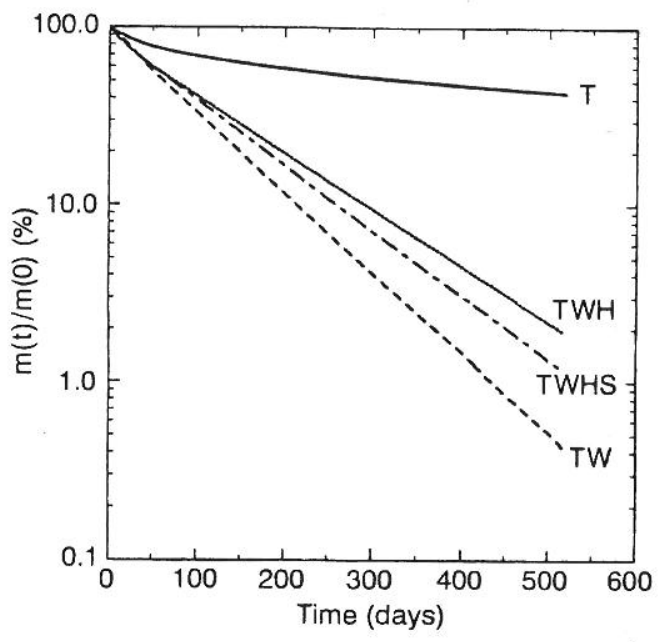

Fig. 10. Ratio of the mass of the Lagrangian particles left in the lagoon to the initial mass, $m(t) / m(0)$, as a function of time for model runs $T, T W, T W H$, and $T W H S$

progresses in all wind-forced simulations. When the tide is the only forcing, however, the time dependency of $m(t)$ departs somewhat from an exponential function during the first 50 days of the simulation.

The turnover time, obtained with the method described, is

$\theta=512,94,128$, and 114 days,

for simulations $T, T W, T W H$, and $T W H S$, respectively. It is no surprise that the turnover time is much larger in the tide-only run than in the simulations where the wind stress is taken into account. The fact that $\theta$ remains of the same order of magnitude throughout the series of 


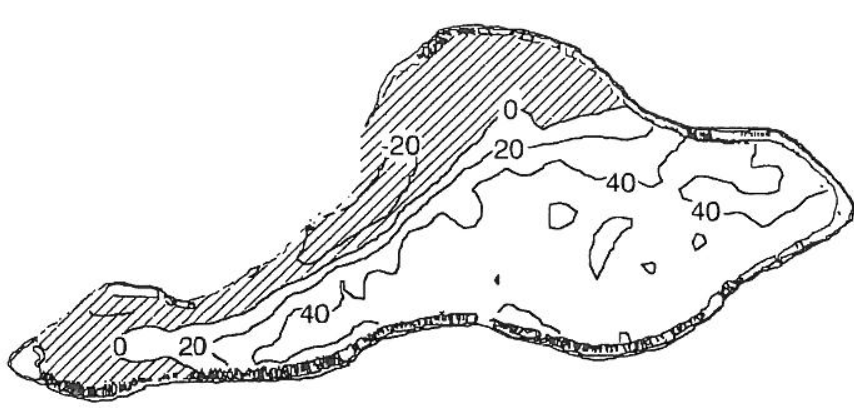

Fig. 11. Difference, expressed in days, between the depth-averaged residence time computed in model run $T W H$ and $T W$. The hatched area corresponds to negative values

wind-forced model runs is consistent with the wind stress being the main flow forcing.

Surprisingly, the hoa inflow increases the turnover time, i.e. the hoa forcing does not simply enhance the overall circulation and, hence, reduce $\theta$ (Wolanski et al. 1994). Instead, as suggested by Fig. 4, a large fraction of the water entering the lagoon through the hoa is likely to follow the most direct route toward the pass, so that it becomes more difficult for water parcels that are to the east of this route to reach the pass. Therefore, the residence time decreases in a narrow strip between the hoa and the pass, and increases to the east of this tongue, i.e. in most of the lagoon (Fig. 11), which eventually raises the lagoon-averaged residence time.

\section{Conclusion}

The cursory comparison of the computed horizontal velocity with in situ measurements (Fig. 3 and 5) was reassuring as to the realism of the numerical simulations. However, thoroughly validating the model was not the primary objective of this work, which, instead, focused on the identification of the processes dominating the hydrodynamics of the Mururoa lagoon. Though the present model results are of a preliminary nature, we conclude that wind stress is the main driving force of the long-term circulation in the Mururoa lagoon. So, according to the definitions of Atkinson et al. (1981), it is believed that the Mururoa lagoon belongs to the class of "deep lagoons", as opposed to "shallow lagoons", in which the circulation is overwhelmingly tidal, rather than wind-driven.

When the wind stress is activated, the distribution of the residence time mainly ensues from the action of the shear effect and the horizontal, depth-averaged, residual velocity, implying that the overturning motion in planes parallel to the wind stress plays only a minor role. If, in addition, stratification is taken into account, the overturning circulation taking place in vertical planes orthogonal to the wind stress is likely to play a significant role. The present sensitivity study also points to the importance of the hoa overflow, which surprisingly tends to increase the turnover time.

Using a constant wind stress was consistent with the wind field being dominated by rather stable trade winds and the acceptance of idealized forcings. This does not imply that the wind stress over the Mururoa lagoon is devoid of variability. Owing to the importance of the wind forcing, as revealed by the present study, analyzing the sensitivity of the long-term transport to the variability of the wind stress is badly needed. This issue will be addressed in a forthcoming article.

It must be kept in mind that the stratification is taken into account in a rather schematic way. Assuming that the Brunt-Väisälä frequency is constant is a weakness of the model. In the future considerable attention will be devoted to the role of the vertical buoyancy gradient. In addition, the drag coefficient allowing us to estimate the wind stress may exhibit a significant space variability (Wolanski and Delesalle 1995), which is not accounted for here.

Finally, the numerical experiments carried out suggest that the turnover time is approximately 100 days. Nonetheless, this estimate must be regarded with some reservation, owing to all the aspects of the model that need to be improved. In particular, it is conceivable that taking into account the variability of the wind stress will modify the modelled turnover time.

Acknowledgements. The present study is funded by the SMSRB. The help of numerous colleagues at UCL and SMSRB is gratefully acknowledged. The authors are indebted to Y. Bourlat, G. Goutière and G. Martin for their vigorous advocacy of the modelling approach to the study of the environmental dynamics at Mururoa. Thanks are also due to K. Black, B. Delesalle, E. Wolanski, and Y. Zech for the advice they gave. E. Deleersnijder is a Research Associate with the National Fund for Scientific Research of Belgium.

\section{References}

Allen CM (1982) Numerical simulation of contaminant dispersion in estuary flow. Proc R Soc London 381 A : 179-194

Atkinson M, Smith SV, Stroup ED (1981) Circulation in Enewetak atoll lagoon. Limnol Oceanogr 26: 1074-1083

Beckers JM (1991) Application of the GHER 3D general circulation model to the Western Mediterranean. J Mar Syst 1:315-332

Beckers JM, Deleersnijder E (1993) Stability of a FBTCS scheme applied to the propagation of shallow-water inertia-gravity waves on various space grids. J Comput Phys 108:95-104

Black KP (1993) The relative importance of local retention and inter-reef dispersal of the neutrally buoyant material on coral reefs. Coral Reefs 12:43-53

Black K P, Gay SL, Andrews JC (1990) Residence times of neutrally buoyant matter such as larvae, sewage or nutrients on coral reefs. Coral Reefs 9:105-114

Blumberg AF, Mellor GL (1987) A description of a three-dimensional coastal ocean circulation model. In: Heaps NS (ed) Threedimensional coastal ocean models. American Geophysical Union, Washington, D.C., pp 1-16

Bolin B, Rodhe H (1973) A note on the concepts of age distribution and transit time in natural reservoirs. Tellus 25:58-62

Bourlat Y, Millies-Lacroix JC, Nazard R (1995) Determination of plutonium radioactivity in Mururoa lagoon water. J Radioanal Nucl Chem 197:393-414

Bowden KF (1965) Horizontal mixing in the sea due to a shearing current. J Fluid Mech 21:83-95

Busch NE (1977) Fluxes in the surface boundary layer over the sea. In: Kraus EB (ed) Modelling and prediction of the upper layers of the ocean. Pergamon, Oxford, pp 72-91

Deleersnijder E, Beckers JM (1992) On the use of the $\sigma$-coordinate system in regions of large bathymetric variations. J Mar Syst $3: 381-390$ 
Deleersmijder E, Luyten PJ (1994) On the practical advantages of the quasi-equilibrium version of the Mellor and Yamada level 2.5 turbulence closure applied to marine modelling. Appl Math Model 18:281-287

Delesalle B, Sournia A (1992) Residence time of water and phytoplankton biomass in coral reef lagoons. Cont Shelf Res 12:939-949

England $M(1995)$ The age of water and ventilation lime-scalcs in a global ocean model. J Phys Oceanogr 25: 2756-2777

Gadd AJ (1978) A split-explicit integration scheme for numerical weather prediction. Q J R Mctcorol Soc 104:569-582

Gallagher BS, Shimada KM, Gonzallez Jr FI, Stroup ED (1971) Tides and currents in Fanning atoll lagoon. Pac Sci 25: 191-205

Galperin B, Kantha LH, Hassid S, Rosati A (1988) A quasi-equilibrium turbulent energy model for geophysical flows. J Atmos Sci $45: 55-62$

Graf WH, Merzi N, Perrinjaquet C (1984) Aerodynamic drag measured at a nearshore platform on lake of Geneva. Arch Meteorol Geophys Bioklimatol Ser 33A:151-173

Hatcher IH, Frith CA (1985) The control of nitrate and ammonium concentrations in a coral reef lagoon. Coral Reefs 4:101-110

Hatcher BG, Imberger J, Smith SV (1987) Scaling analysis of coral reef systems: an approach to problems of scalc. Coral Recfs 5: $171-181$

Hunter JR, Craig PD, Phillips HE (1993) On the use of random walk models with spatially variable diffusivity. J Comput Phys $106: 366-376$

James ID (1986) A front resolving sigma coordinate model with a simple hybrid advection scheme. Appl Math Model 10:87-92

Kimmerer WJ, Walsh TW (1981) Tarawa atoll lagoon: circulation, nutrient fluxes, and the impact of human waste. Micronesica 17: $161-179$

Mellor GL, Yamada T (1982) Development of a turbulence closure model for geophysical fluid problems. Rev Geophys Space Phys $20: 851-875$

Nihoul JCJ (1984) A three-dimensional general marine circulation model in a remote sensing perspective. Ann Geophys 2:433-442

Okubo A (1980) Diffusion and ecological problems: malhemalical models. Springer-Verlag, Berlin Heidelberg New York
Patankar SV (1980) Numerical heat transfer and fluid flow. Hemisphere Publishing, New York

Rancher J (1995) Courantologie à proximité des flancs et devant les passes des atolls de Mururoa et de Fangataufa. Rapport $01 /$ SMSRB/NP, Service Mixte de Surveillance Radiologique et Biologique de l'homme et de l'environnement, Commissariat i) l'Finergic $\Lambda$ lomique. Momblilery, France

Rancher J. (hevalier f (1989) Rapport preliminaire sur les cohanges lagon-océan au niveau de la passe de Mururoa. Rapport 5I/SMSR/DIR/89, Scrvice Mixte de Sécurité Radiologique Commissarial a l’Energic Atomique, Monthléry, France

Ribbe J, Tomczak M (1990) An impact assessment for the French nuclear weapon test sites in French Polynesia. Mar Pollut Bull $21: 536-542$

Rougerie F, Ricard M. Mazaury E (1984) Le lagon de l'atoll de Mururoa. Notes et Documents Océanographiques, vol 16, ORSTOM, Papeete

Ruddick KG, Deleersnijder E, Luyten PJ, Ozer J (1995) Haline stratification in the Rhine-Meuse freshwater plume: a threedimensional model sensitivity analysis. Cont Shell Res 15: $1597-1630$

SHOM (Service Hydrographique et Océanographique de la Marine) (1.994) Annuaire des Marées des Ports d'Outre-Mer, SHOM Edition, Paris

Smith SV, Pesret P (1974) Processes of carbon dioxide flux in the Fanning Island lagoon. Pac Sci 28: 225-245

Takeoka H (1984) Fundamental concepts of exchange and transport time scales in a coastal sea. Cont Shelf Res $3: 311-326$

von Arx WS (1948) The circulation systems of Bikini and Rongelap lagoons. Trans Am Geophys Union 29:861-870

Wolanski E, Delesalle B (1995) Wind-driven upwelling in Opunohu Bay, Moorea, French Polynesia. Estuar Coastal Shelf Sci $40: 57-66$

Wolanski E, Delesalle B, Gibbs R (1994) Carbonate mud in Mataiva atoll, French Polynesia: suspension and export. Mar Pollut Bull $29: 36-41$

Zimmerman JTF (1976) Mixing and flushing of tidal embayments in the Western Dutch Wadden Seal. Part 1: distribution of salinity and calculation of mixing time scales. Neth J Sea Res 10: 149-191 
